\title{
Decompressive craniectomy in paediatric traumatic brain injury: a systematic review of current evidence
}

\author{
Maddalena Ardissino $^{1}$ (D) Alice Tang $^{1} \cdot$ Elisabetta Muttoni $^{2} \cdot$ Kevin $^{\text {Tsang }}{ }^{3}$
}

Received: 17 July 2018 / Accepted: 5 September 2018 / Published online: 13 September 2018

(C) The Author(s) 2018

\begin{abstract}
Introduction Paediatric traumatic brain injury (pTBI) is one of the most frequent neurological presentations encountered in emergency departments worldwide. Every year, more than 200,000 American children suffer pTBIs, many of which lead to long-term damage.

Objectives We aim to review the existing evidence on the efficacy of the decompressive craniectomy (DC) in controlling intracranial pressure (ICP) and improving long-term outcomes in children with pTBI.

Methods A comprehensive search of the MEDLINE and EMBASE databases led to the screening of 212 studies, 12 of which satisfied inclusion criteria. Data extracted included the number and ages of patients, Glasgow Coma Scale scores at presentation, treatment protocols and short- and long-term outcomes.

Results Each of the nine studies including ICP as an outcome reported that it was successfully controlled by DC. The 6-12 month outcome scores of patients undergoing DC were positive, or superior to those of medically treated groups in nine of 11 studies. Mortality was compared in only two studies, and was lower in the DC group in both.Very few studies are currently available investigating short- and long-term outcomes in children with TBI undergoing DC.

Conclusion The currently available evidence may support a beneficial role of DC in controlling ICP and improving long-term outcomes.
\end{abstract}

Keywords Paediatric traumatic brain injury, TBI · Decompressive craniectomy $\cdot$ Surgery $\cdot$ Intracranial pressure, ICP · Outcomes · Management

\section{Introduction}

\section{Background}

Paediatric traumatic brain injury (pTBI) is one of the most frequent neurological emergencies affecting children throughout the world: ten million injuries lead to hospitalisation or death every year [1]. In the USA alone, approximately 230,000 children suffer a TBI every year, and these lead

Maddalena Ardissino

ma5713@imperial.ac.uk

1 Imperial College School of Medicine, Imperial College London, London SW7 2AZ, UK

2 St. Helens and Knowsley Teaching Hospitals, Whiston Hospital NHS Trust, Liverpool, UK

3 Department of Neurosurgery, Imperial College Healthcare NHS Trust, Charing Cross Hospital, London, UK to even more severe and long-lasting neurological disabilities than those occurring in adolescents or adults [2]. Despite this, there is little evidence on which to base protocols for the management of pTBI as most of the treatment algorithms are founded on experience gained in adults and adapted on the basis of subtle differences in physiology and anatomy. However, since the introduction of the 2012 guidelines, a number of studies have been published concerning especially the surgical management of adult and pTBI, the results of which can be considered for future modifications of management protocols.

\section{Aims}

The aim of this review is to summarise and assess current methods of surgically managing pTBI, concentrating on the use of decompressive craniectomy (DC) as a means of reducing intracranial pressure (ICP) in the short term, and improving rehabilitative outcomes in the long term. Although it is still a subject considerable debate, it has 
been shown that DC effectively decreases ICP and its fluctuations, and may increase cerebral perfusion pressure [3], it has also been shown to be more economically effective than medical management approaches such as the use of barbiturate-induced coma [4]. However, its impact on the clinical outcomes of TBI patients has yet to be fully ascertained. A systematic review was carried out with the aim of summarising the currently available evidence on the effect of the DC on ICP reduction in the short term, and rehabilitation outcomes in the long term.

This review considers the published evidence concerning the short- and long-term outcomes of DC in children pTBI, as well as the most important recent studies of its therapeutic role in adult patients.

\section{Methods}

\section{Literature search}

This systematic review was made following the guidelines proposed in the PRISMA statement [5]. The MEDLINE and EMBASE databases were searched using the terms '(paediatric traumatic brain injury) AND (decompressive craniectomy)'. Only studies published in English were considered.

Of the 617 studies published up to October 2017, we selected the randomised clinical trials (RCTs), case series or two-arm studies that involved patients aged $<18$ years, included TBI patients who underwent DC to control ICP, and measured long-term ( $>4$ weeks) outcomes. Individual case reports were excluded, as were studies that did not provide quantitative data or were designed to answer different questions (e.g. those investigating complications or outcome predictions).

Twelve of the 212 screened studies satisfied our selection criteria (one RCT, and 11 case series involving a total of 260 patients), and were read in full and analysed by all of the authors of this review. The selection process is outlined in Fig. 1.

\section{Data analysis}

The extracted data included the names of the authors and the year of study publication, the number and age ranges of the patients involved, Glasgow Coma Scale (GCS) scores at the time of presentation, treatment protocols, and shortand long-term outcomes and mortality. This information was summarised and reviewed by three reviewers independently (MA, EM and AT), and further evaluated by the senior author (KT). Two of the reviewers independently assessed the quality of the data using the GRADE scoring system of the British Medical Journal (BMJ) [6], and the risk of bias was analysed using the Cochrane risk of bias tool [7].

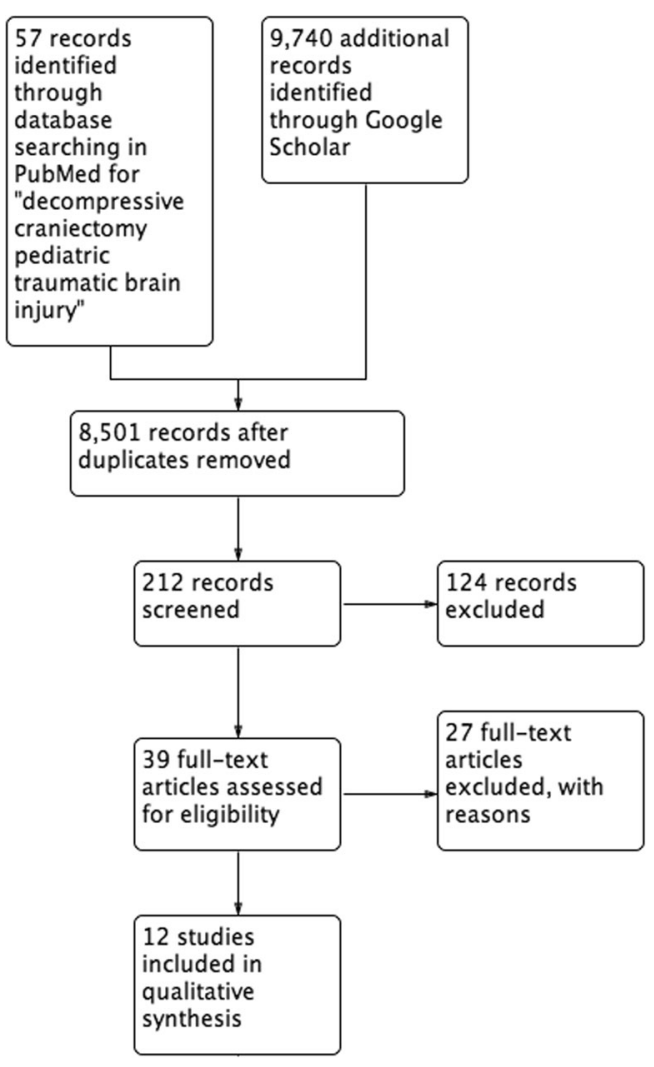

Fig. 1 PRISMA flowchart of study selection

\section{Results}

\section{Quality assessment}

The only RCT that met the inclusion criteria [8] was judged to be at risk of bias on the basis of the Cochrane risk of bias tool because of incomplete information regarding the blinding of the outcome measurer. A number of studies enrolled only a few patients, and some did not fully describe outcomes, or assess and control for confounding factors. Overall, the number of patients included in the 12 studies analysed is extremely low, varying from 5 to 53 (median 17) per study. Table 1 shows the level of the quality of evidence for each study on the basis of the BMJ's GRADE scoring system, and the risk of bias was assessed using RevMan [20].

\section{Effect of DC on ICP}

Of the 12 studies reviewed, nine included ICP as a short-term outcome. All nine reported that ICP was successfully reduced by DC and that the patients required fewer ICP control interventions. Two studies directly compared ICP control in patients receiving medical treatment (MT) and those undergoing DC. Cho et al. [9] found an $80 \%$ reduction in ICP in DC patients, which was greater than that observed in the MT group $(p<0.05)$, and the RCT by Taylor et al. [8] also found 


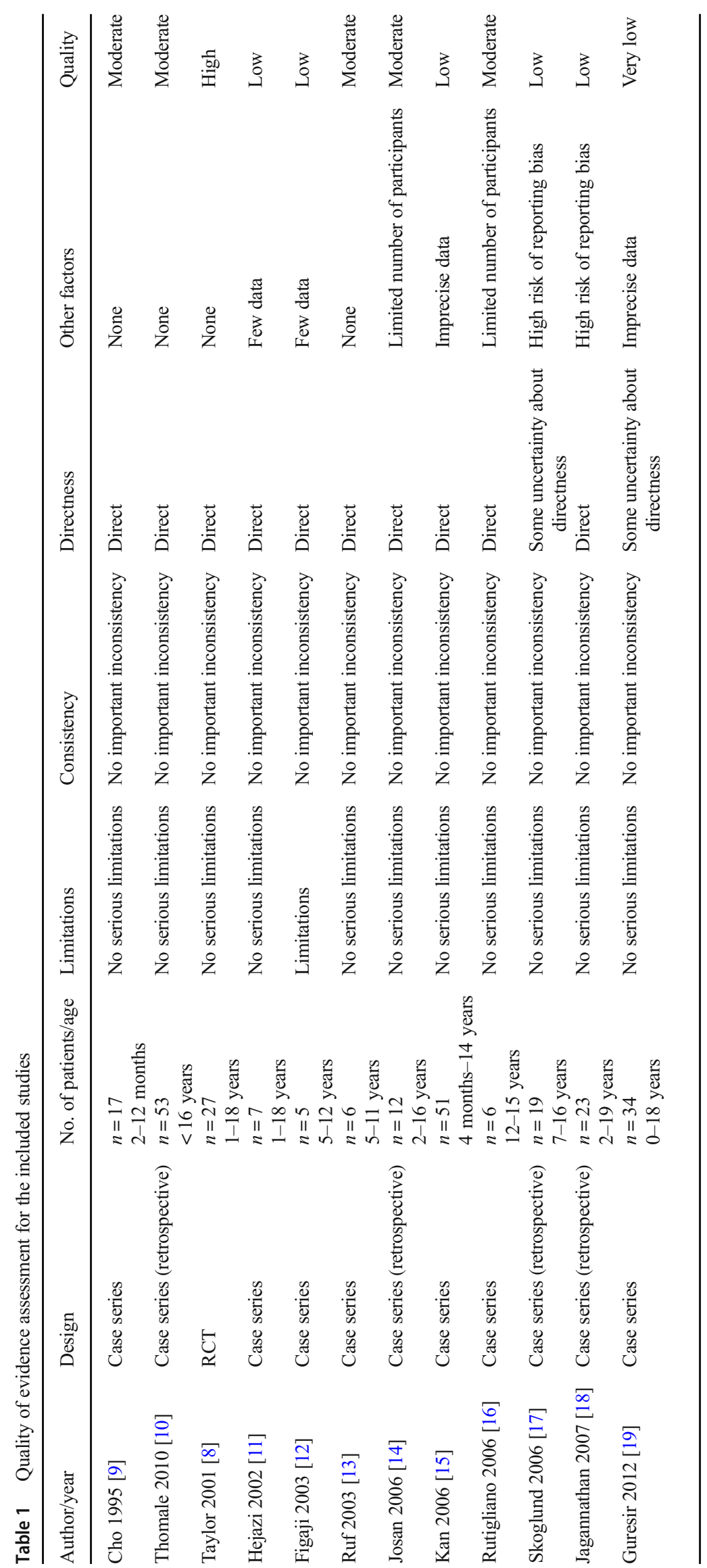




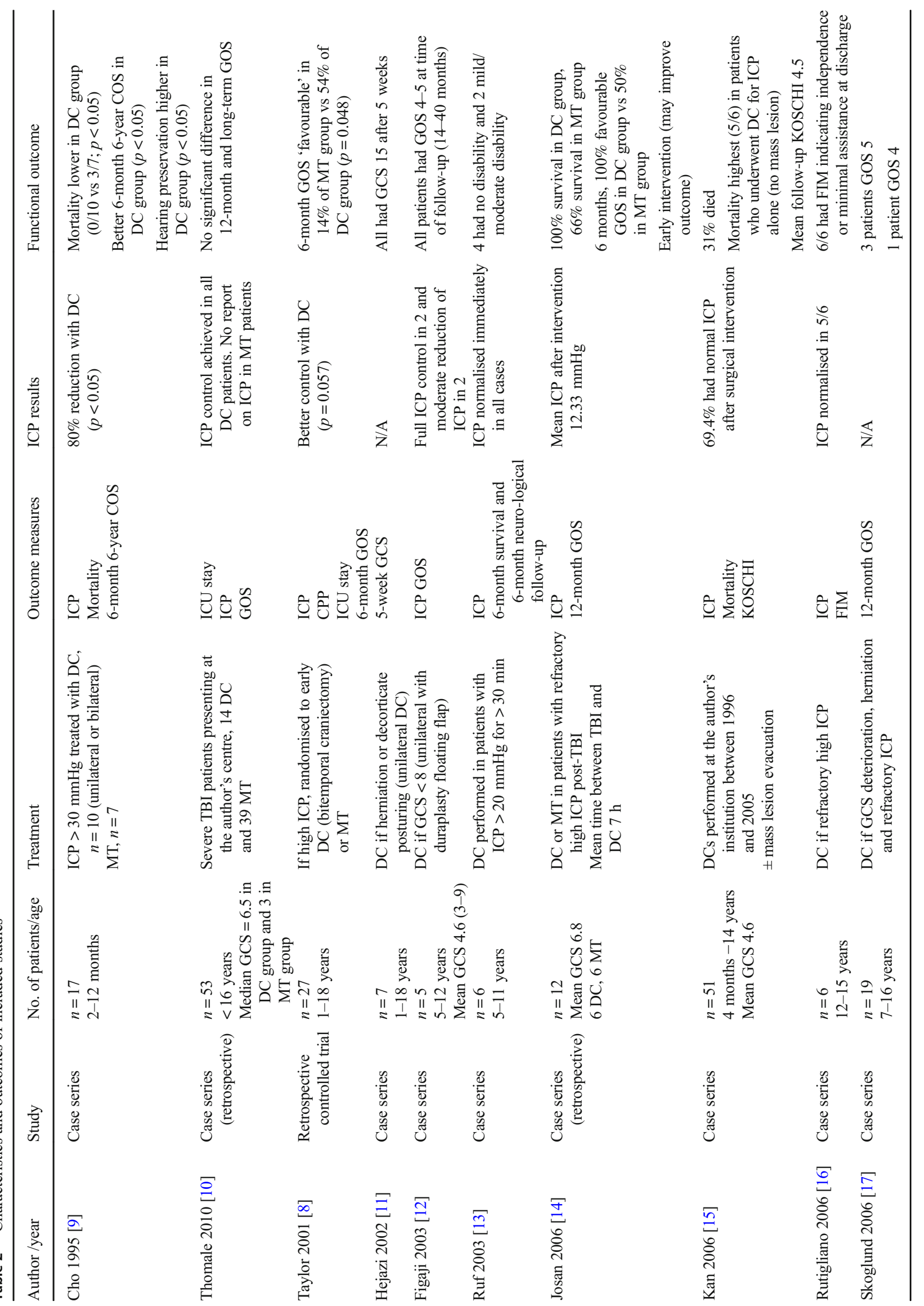


that DC led to better ICP control than MT, although the difference was not statistically significant $(p=0.057)$. The rates of ICP control achieved in all of the other studies [10, 12-16, 18] ranged from 69.4 to $100 \%$ (Table 2).

\section{Effect of DC on mortality}

Only two of the studies compared mortality among the patients undergoing DC and those receiving MT. Cho et al. [9] found that mortality was significantly lower in the patients who underwent DC ( $0 / 10$ vs $3 / 7 ; p<0.05)$, and Josan et al. [14] recorded higher survival rates (100\% vs 66\%) (Table 2$)$.

\section{Effect of DC on long-term outcomes}

The method of assessing long-term outcomes varied: the most widely used scoring system was the original Glasgow Outcomes Scale (GOS) or the Extended Glasgow Outcomes Scale (GOS-E), and several studies included other systems (the Functional Independence Measure, Children's Outcome Score, King's Outcome Scale for Closed Head Injury and quality of life scales). These systems generally assess functional ability and independence, return to school and performance in doing everyday activities but, given their heterogeneity, we qualitatively compared the results by dividing them into positive or negative functional outcomes. Complete recovery, or a mild disability that does not interfere with independence or activities, was regarded as a positive outcome, and severe disability, dependency, vegetative state and mortality as negative outcomes.

Ten studies reported positive outcomes in the patients who underwent DC $[8,9,11-19]$. Four directly compared the follow-up GOS scores of the patients who underwent DC with those of the patients receiving MT $[8-10,14]$ (Table 2). Cho et al. [9] found that the scores assigned between 6 months and 6 years after a TBI were significantly better in the patients who underwent DC $(p<0.05)$. This is in line with the results of the retrospective study of Josan et al [14]: 6 months after their TBIs, all of the DC patients were assigned a favourable GOS score as against $50 \%$ of those who received MT. Taylor et al. [8] also found that the DC group had a higher incidence of favourable GOS scores after 6 months (54\% vs $14 \%$ in the MT group), but Thomale et al. [10] did not find any significant difference in long-term GOS scores between the two groups.

\section{Discussion}

The use of DC to treat high ICP in paediatric and adult TBI patients has long been a subject of debate. The recommendations for surgery in children are even less clear than those included in the adult guidelines because of the severe lack of 
clinical evidence [21]. As highlighted in this review, it has been consistently found that ICP is well controlled by DC in children with TBI in the short term, but the correlation between successful ICP control and long-term clinical outcomes is more questionable. Furthermore, the existing evidence is derived from studies with high risk of bias, and containing low patient numbers. The current guidelines [21] recommend DC when performed together with other surgical procedures such as haemorrhage evacuation, or if there is strong suspicion of herniation, but its use as a stand-alone procedure to relieve ICP in patients without herniation is limited to those with intracranial hypertension ( $>25 \mathrm{mmHg}$ ) showing signs of neurological deterioration, or high ICP refractory to optimal MT.

The findings of the retrospective case series and the RCT reviewed generally indicate that DC has a positive effect in controlling ICP, though the quality of evidence is generally low. Hejazi's [11] study reported a full recovery in five out of six patients who underwent the procedure, Figaji et al. [12] similarly reported notable improvements in neurological function in a cohort of patients on whom DC was performed following neurological deterioration, and similar findings were reported by Ruf et al. [13] and others. The only RCT was conducted by Taylor et al. [8], who compared the outcomes of DC and MT in respectively 27 children with refractory an ICP of $>30 \mathrm{mmHg}$ and found that they were much worse in the children receiving MT. However, only two studies compare ICP control directly between patients receiving MT and those undergoing DC. Mortality was only analysed in two studies with low patient numbers [9, 14], of 12 and 17 respectively. More studies looked at long-term outcomes; however, outcome scales used to compare these were variable; it is therefore hard to draw general conclusions from them.

Although adult studies do not provide direct evidence concerning the paediatric use of DC, it is important to consider

Table 3 Characteristics and outcomes of recent important studies in the adult population

\begin{tabular}{|c|c|c|c|c|c|}
\hline Author/year & $\begin{array}{l}\text { Study type no. } \\
\text { Patients } \\
\text { Age }\end{array}$ & Treatment & $\begin{array}{l}\text { Outcome } \\
\text { measures }\end{array}$ & Results, outcomes & $\begin{array}{l}\text { Study quality } \\
\text { and bias }\end{array}$ \\
\hline $\begin{array}{l}\text { Cooper } \\
2011 \text { [22] }\end{array}$ & $\begin{array}{l}\text { Randomised } \\
\quad \text { clinical trial } \\
n=155\end{array}$ & $\begin{array}{l}\text { Patients with ICP } \\
>20 \mathrm{mmHg} \\
\text { for }>15 \mathrm{~min} \\
\text { Randomly allocated } \\
\text { to DC or MT }\end{array}$ & $\begin{array}{l}\text { ICP } \\
6 \text {-month GOS-E }\end{array}$ & $\begin{array}{l}\text { ICP } \\
\text { DC group had fewer hours with } \\
\text { high ICP than MT group } \\
(p<0.001) \\
\text { DC group had fewer days in ICU } \\
\text { DC group had fewer ICP control } \\
\text { interventions } \\
\text { Outcomes } \\
\text { DC group had worse GOS-E } \\
\text { (OR 1.84, CI 1.05-3.24; } \\
p=0.03) \\
\text { DC group at greater risk of } \\
\text { unfavourable outcomes (death, } \\
\text { severe disability and vegetative } \\
\text { state), OR } 2.21, \text { CI } 1.14-4.26 ; \\
p=0.02\end{array}$ & $\begin{array}{l}\text { ICP threshold does not } \\
\text { reflect clinical } \\
\text { guidelines for DC } \\
\text { Mismatch in severity of } \\
\text { TBI between DC and } \\
\text { MT group }\end{array}$ \\
\hline $\begin{array}{l}\text { Timofeev } \\
2006 \text { [25] }\end{array}$ & $\begin{array}{l}\text { Retrospective } \\
\quad \begin{array}{l}\text { observational } \\
\text { study } \\
n=49 \\
\text { Age 9-67 years }\end{array}\end{array}$ & $\begin{array}{l}\text { DC, bilateral or unilateral } \\
\text { in patients with } \\
\text { persistently high ICP }\end{array}$ & $\begin{array}{l}\text { 6-month GOS } \\
\text { and SF-36 QOL } \\
\text { questionnaire }\end{array}$ & $\begin{array}{l}\text { Outcomes at } 6 \text { months, } 30(61.2 \%) \\
\text { had good outcomes, } 10(20.4 \%) \\
\text { had severe disability and } \\
9(18.4 \%) \text { died }\end{array}$ & $\begin{array}{l}\text { No comparison with } \\
\text { untreated patients } \\
\text { No randomisation or } \\
\text { control for } \\
\text { confounders }\end{array}$ \\
\hline $\begin{array}{l}\text { Hutchinson } \\
2016 \text { [24] }\end{array}$ & $\begin{array}{l}\text { Randomised } \\
\quad \text { clinical trial } \\
n=408 \\
\text { Age } 10-65 \text { years }\end{array}$ & $\begin{array}{l}\text { Refractory ICP }>25 \mathrm{mmHg} \\
\text { Randomly allocated to } \\
\text { DC or MT }\end{array}$ & $\begin{array}{l}\text { Mortality } \\
\text { 6-month GOS }\end{array}$ & $\begin{array}{l}\text { ICP } \\
\text { DC group had fewer hours with } \\
\text { high ICP than MT group } \\
(p<0.001) \\
\text { Outcomes } \\
\text { DC group had lower mortality } \\
\text { rate } \\
\text { MT group had lower severe } \\
\text { disability rate } \\
\text { Rates of good recovery and } \\
\text { moderate disability were the } \\
\text { same }\end{array}$ & \\
\hline
\end{tabular}

$D C$ decompressive craniectomy, $M T$ medical therapy, ICP intracranial pressure, GOS Glasgow Outcome Score 
their results as supplementary information not least because there are more high-quality studies referring to adults. The DECRA study (decompressive craniectomy in diffuse traumatic brain injury) found that patients with refractory intracranial hypertension $(>20 \mathrm{mmHg}$ ) who underwent $\mathrm{DC}$ required shorter ICU stays and fewer interventions to control ICP, but experienced worse long-term clinical outcomes [22]. However, questions have been raised about the potential bias of this study mainly because the randomisation process led to unbalanced cohorts with discrepancies in the severity of TBI (greater in the DC group) and GCS scores upon admission; furthermore, it has been pointed out that the definition of refractory raised ICP ( $>20 \mathrm{mmHg}$ for $>15 \mathrm{~min}$ ) does not reflect clinical practice [23]. On the other hand, the RESCUE-ICP (trial of decompressive craniectomy for traumatic intracranial hypertension) trial found that the use of DC in adult patients with an ICP of $>25 \mathrm{mmHg}$ was associated with fewer deaths and cases of severe disability than medical management, although it was also associated with a higher incidence of patients experiencing a vegetative state. There was no difference in the incidence of 'good outcomes' between the two groups [24]. Table 3 summarises the results of the most important recent studies of adults undergoing DC.

\section{Conclusions}

This review aims to summarise the presently available evidence in the treatment of paediatric traumatic brain injury using decompressive craniectomy versus medical treatment. The evidence considered in this review indicates a possible benefit in use of DC in patients with pTBI for reducing high ICP $(>25 \mathrm{mmHg})$ that is refractory to medical treatment. However, the quality of evidence remains extremely low, and there is very little evidence from RCTs to indicate whether this correlates with long-term benefits in the paediatric population. The findings of retrospective studies generally indicate a beneficial effect with improved long-term neurological recovery, but they are sometimes inconsistent and their quality varies because of differences in the patient age, the criteria for and timing of surgery, injury factors, rating scales used and the use of concomitant medical treatment. Overall, though available evidence unanimously indicates a short-term benefit in using DC to reduce ICP and mortality, and possible long-term rehabilitative improvement, the assessment of evidence quality carried out highlights the lack of evidence in the field, and further high-quality studies on larger patient numbers are certainly required.

\section{Compliance with ethical standards}

Conflict of interest On behalf of all the authors, the corresponding author states that there is no conflict of interest.
Open Access This article is distributed under the terms of the Creative Commons Attribution 4.0 International License (http:// creativecommons.org/licenses/by/4.0/), which permits unrestricted use, distribution, and reproduction in any medium, provided you give appropriate credit to the original author(s) and the source, provide a link to the Creative Commons license, and indicate if changes were made.

\section{References}

1. Thurman DJ (2014) The epidemiology of traumatic brain injury in children and youths: a review of research since 1990. J Child Neurol 31(August):1-8

2. Levin HS, Eisenberg HM, Wigg NR, Kobayashi K (1982) Memory and intellectual ability after head injury in children and adolescents. Neurosurgery 11(5):668-673

3. Whitfield PC, Patel H, Hutchinson PJ, Czosnyka M, Parry D, Menon D, Pickard JD, Kirkpatrick PJ (2001) Bifrontal decompressive craniectomy in the management of posttraumatic intracranial hypertension. Br J Neurosurg 15(6):500-507

4. Alali AS, Naimark DMJ, Wilson JR, Fowler RA, Scales DC, Golan E, Mainprize TG, Ray JG, Nathens AB (2014) Economic evaluation of decompressive craniectomy versus barbiturate coma for refractory intracranial hypertension following traumatic brain injury. Crit Care Med 42(10):2235-2243

5. BMJ (OPEN ACCESS), Moher D, Liberati A, Tetzlaff J, Altman DG, The PRISMA Group (2009) Preferred reporting items for systematic reviews and meta-analyses: the PRISMA statement. BMJ 339:b2535

6. Atkins D, Best D, Briss PA, Eccles M, Falck-Ytter Y, Flottorp S, Guyatt GH, Harbour RT, Haugh MC, Henry D, Hill S, Jaeschke R, Leng G, Liberati A, Magrini N, Mason J, Middleton P, Mrukowicz J, O'Connell D, Oxman AD, Phillips B, Schunemann HJ, Edejer T, Varonen H, Vist GE, Williams JW Jr, Zaza S (2004) Grading quality of evidence and strength of recommendations. BMJ 328(7454): 1490

7. Higgins JPT, Altman DG, Gøtzsche PC, Jüni P, Moher D, Oxman AD, Savovic J, Schulz KF, Weeks L, Sterne JAC (2011) The Cochrane Collaboration's tool for assessing risk of bias in randomised trials. BMJ 343:d5928

8. Taylor A, Butt W, Rosenfeld J, Shann F, Ditchfield M, Lewis E, Klug G, Wallace D, Henning R, Tibballs J (2001) A randomized trial of very early decompressive craniectomy in children with traumatic brain injury and sustained intracranial hypertension. Childs Nerv Syst 17(3): 154-162

9. Cho DY, Wang YC, Chi CS (1995) Decompressive craniotomy for acute shaken/impact baby syndrome. Pediatr Neurosurg 23(4):192198

10. Thomale UW, Graetz D, Vajkoczy P, Sarrafzadeh AS (2010) Severe traumatic brain injury in children-a single center experience regarding therapy and long-term outcome. Childs Nerv Syst 26:15631573

11. Hejazi N, Witzmann A, Fae P (2002) Unilateral decompressive craniectomy for children with severe brain injury. Report of seven cases and review of the relevant literature. Eur J Pediatr 161(2):99 104

12. Figaji AA, Fieggen AG, Peter JC (2003) Early decompressive craniotomy in children with severe traumatic brain injury. Childs Nerv Syst 19(9):666-673

13. Ruf B, Heckmann M, Schroth I, Hugens-Penzel M, Reiss I, Borkhardt A, Gortner L, Jodicke A (2003) Early decompressive craniectomy and duraplasty for refractory intracranial hypertension in children: results of a pilot study. Crit Care 7(6):R133-R138 
14. Josan VA, Sgouros S (2006) Early decompressive craniectomy may be effective in the treatment of refractory intracranial hypertension after traumatic brain injury. Childs Nerv Syst 22:1268-1274

15. Kan P, Amini A, Hansen K, White GL, Brockmeyer DL, Walker ML, Kestle JRW (2006) Outcomes after decompressive craniectomy for severe traumatic brain injury in children. $\mathrm{J}$ Neurosurg 105(5 Suppl):337-342

16. Rutigliano D, Egnor MR, Priebe CJ, McCormack JE, Strong N, Scriven RJ, Lee TK (2006) Decompressive craniectomy in pediatric patients with traumatic brain injury with intractable elevated intracranial pressure. J Pediatr Surg 41:83-87 discussion 83-87

17. Skoglund TS, Eriksson-Ritzen C, Jensen C, Rydenhag B (2006) Aspects on decompressive craniectomy in patients with traumatic head injuries. J Neurotrauma 23:1502-1509

18. Jagannathan J, Okonkwo DO, Dumont AS, Ahmed H, Bahari A, Prevedello DM, Jane JA Sr, Jane JA Jr (2007) Outcome following decompressive craniectomy in children with severe traumatic brain injury: a 10-year single-center experience with long-term follow up. J Neurosurg 106(4 Suppl):268-275

19. Güresir E, Schuss P, Seifert V, Vatter H (2012) Decompressive craniectomy in children: single-center series and systematic review. Neurosurgery 70(4):881-888

20. Cochrane (2014) Review Manager (RevMan) version 5.3. The Nordic Cochrane Centre, Copenhagen
21. Kochanek PM, Adelson PD, Ashwal S, Bell MJ, Bratton S, Carson S, Chesnut RM, Ghahar J, Goldstein B, Grant GA, Kissoon N, Peterson K, Selden NR, Tong KA, Tasker RC, Vavilala MS, Wainwright MS, Warden CR (2012) Chapter 12. Decompressive craniectomy for the treatment of intracranial hypertension. Pediatr Crit Care Med 13:S53-S57

22. Cooper DJ, Rosenfeld JV, Murray L, Arabi YM, Davies AR, D’Urso P, Kossmann T, Ponsford J, Seppelt I, Reilly P, Wolfe R (2011) Decompressive craniectomy in diffuse traumatic brain injury. N Engl J Med 364(16):1493-1502

23. Honeybul S, Ho KM, Lind CRP (2013) What can be learned from the DECRA study. World Neurosurg 79(1):159-161

24. Hutchinson PJ, Kolias AG, Timofeev IS, Corteen EA, Czosnyka M, Timothy J, Anderson I, Bulters DO, Belli A, Eynon CA, Wadley J, Mendelow AD, Mitchell PM, Wilson MH, Critchley G, Sahuquillo J, Unterberg A, Servadei F, Teasdale GM, Pickard JD, Menon DK, Murray GD, Kirkpatrick PJ (2016) Trial of decompressive craniectomy for traumatic intracranial hypertension. N Engl J Med 375(12):1119-1130

25. Timofeev I, Kirkpatrick PJ, Corteen E, Hiler M, Czosnyka M, Menon DK, Pickard JD, Hutchinson PJ (2006) Decompressive craniectomy in traumatic brain injury: outcome following protocol-driven therapy. Acta Neurochir Suppl 96:11-16 